\title{
Parasitic infection in blackbuck (Antilope cervicapra Linnaeus, 1758) of Blackbuck Conservation Area, Bardiya and Shuklaphanta Wildlife Reserve, Kanchanpur, Western Nepal
}

\author{
Ram Bahadur Chaudhary and Mahendra Maharjan*
}

\author{
Central Department of Zoology, Tribhuvan university, Kathmandu, Nepal
}

\begin{abstract}
Blackbuck (Antilope cervicapra) is Near Threatened species which are conserved in blackbuck Conservation Area (BCA), Khairapur, Bardiya and Shuklaphanta Wildlife Reserve (SWR), Kanchanpur district. The present study was conducted to determine the parasitic infection in blackbuck of BCA and SWR. A total of 150 and 70 fresh faecal samples of blackbuck were collected from BCA and SWR respectively and examined by floatation, sedimentation and Stoll's counting technique. The overall prevalence of GI parasites was found to be $90.00 \%$. The protozoan and helminthic parasitic prevalence revealed $55 \%$ and $89 \%$ respectively in both the study area. Blackbuck of BCA were found to be infected with 12 different species of parasites which includes Entamoeba sp. (20\%) and Eimeria sp. (45.33\%) among protozoa; Paramphistomum sp. (25.33\%) and Fasciola sp. (17.33\%) among trematodes; Moniezia sp. (14\%) among cestode; Trichostrongylus sp. (75.33\%), Ascaris sp. (57.33\%), Haemonchus sp. (18\%), Strongyloides sp. (16\%), Bunostomum sp. (12.67\%), Trichuris sp. (6\%) and Oxyuris sp. $(4.67 \%)$ among nematodes; while blackbuck of SWR were found to be infected with 10 different parasitic genera, i.e. Entamoeba sp. (8.57\%) and Eimeria sp. (51.43\%) among protozoa; Paramphistomum sp. (38.57\%), Fasciola sp. (21.43\%) and Schistosoma sp. (7.14\%) among trematodes; Trichostrongylus sp. (55.71\%), Ascaris sp. (38.57\%), Haemonchus sp. (14.28\%), Strongyloides sp. (12.86\%) and Bunostomum sp. (2.86\%) among nematodes. The present findings provide some baseline information on the parasitic burden in Blackbuck and help to formulate appropriate strategies to mitigate the endoparasitic problem of blackbuck in SWR and BCA.
\end{abstract}

Key words: Blackbuck, GI parasites, wildlife, Blackbuck Conservation Area, Shuklaphanta Wildlife Reserve

\section{Introduction}

Blackbuck (Antilope cervicapra), locally known as Krishnasaar, is an elegant, gazelle-like animal regarded as the most handsome member of the Bovidae family and order 'Artiodactyla'. According to the coat, color, length and the shape of the horn, there are four sub-species of Antilope cervicapra, i.e. Antilope cervicapra cervicapra, A cervicapra centralis, A cervicapra rupicapra and A. cervicapra rajputane (Corbett \& Hill, 1977). The blackbuck is Near Threatened which belongs to IUCN Red List of Threatened Species (IUCN, 2008).

The blackbuck is typically distributed in India, Pakistan and Nepal (Lydekker, 1924). Ranjitsinh (1989) estimated a total of 45,000 animals in India. The blackbuck was extinct in Bangladesh and also became extinct in Pakistan in 1970s, but 10 animals were reintroduced from Texas, USA in Lal Sunhara National Park of Sindh Provience of Pakistan (Burton \& Burton, 1987). About 43,600 Blackbucks were introduced to Argentina and the USA (Mallon \& *Corresponding author, email address: mmaharjan@cdztu.edu.np
Kingswood, 2001). In Nepal, before the malaria eradication programme, blackbuck was commonly found in Eastern and Western Tarai; but later the population of blackbuck declined gradually. Scattered population of blackbuck occurred in Kanchanpur, Bardiya and Banke districts in Western Nepal as late as 1960s (Pradhan et al., 1999). Blackbucks are restricted to Khairapur, Bardiya; few are in captive in Central Zoo, Nepalgunj mini zoo and semi-captive enclosures at Mrigasthali, Kathmandu (Khanal, 2006). Now, blackbucks are also restricted to Hirapur phanta of SWR, Kanchanpur (DNPWC, 2012). Twenty eight blackbucks were re-introduced to Hirapur phanta of SWR, Kanchanpur (DNPWC, 2012). In 2012, the population of blackbuck was estimated to be 287 in blackbuck Conservation Area, Khairapur (Shah, 2012).

The animals suffer from a variety of infectious and non-infectious diseases, particularly that of parasitic origin (Akhter \& Arshad, 2006; Lama et al., 2015). The major concern with wild ruminants 
like blackbuck is a decrease in animal health and even death. In nature, wild animals live on large areas and have consequently a low genetic resistance against parasitic infections because of low exposure (Muoria et al., 2005) and practically animal is not free from parasitic infection (Hossain, 2012). Blackbucks are susceptible to various kinds of parasitic infections like coccidiosis, paramphistomiasis, fascioliasis, schistosomiasis, taeniasis nematodiasis (Thornton et al., 1973). Mortality and health problem diagnosed mainly in young adult male and pregnant blackbucks include food shortage and malnutrition, overcrowding and parasitism in USA (Thornton et al., 1973). Mortality also diagnosed in blackbuck of BCA, Khairapur, Nepal due to different viral diseases like diphtheria, foot and mouth disease, etc. (DNPWC, 2009). Generally, blackbuck can be infected with different types of endoparasites. The major gastro-intestinal parasites reported in blackbuck includes Coccidia, Taenia bydatigena, Camelostrongylus sp., Haemonchus sp., Trichostrongylus sp., Nematodirus sp., Oesophagostomum sp., Trichuris sp., Paramphistomum sp.,
Schistosoma sp., Moniezia sp. (Ban, 2012; Frooq et al., 2012; Khanal, 2006). Out of these reported parasites, Camelostrongylus mentulatus is most dreadful nematode to blackbuck and also associated with chronic emaciation and death of dominant adult males (Flach \& Swell, 1987).

\section{Materials and Methods \\ Study area}

The study was conducted in BCA of Khairapur, Bardiya district and SWR of Kanchanpur district Nepal. The blackbuck Conservation Area is the only one conservation area of Tarai region, which is located at Khairapur, Bardiya district in Western Nepal. It covers an area of $16.95 \mathrm{~km}^{2}$ which includes the core habitat of $5.27 \mathrm{~km}^{2}$ with circumference of $10.25 \mathrm{~km}$ and peripheral area of villages and settlements spreading over $11.68 \mathrm{~km}^{2}$. The SWR is a protected area, located in the Far western low-land Tarai towards the southwest edge of Nepal. It covers $305 \mathrm{~km}^{2}$ of open grassland, forests, riverbed, and tropical wetlands at an altitude of 174 to 1,386 meters. The blackbuck habitat is situated in Hirapur Phanta of SWR (Fig. 1).

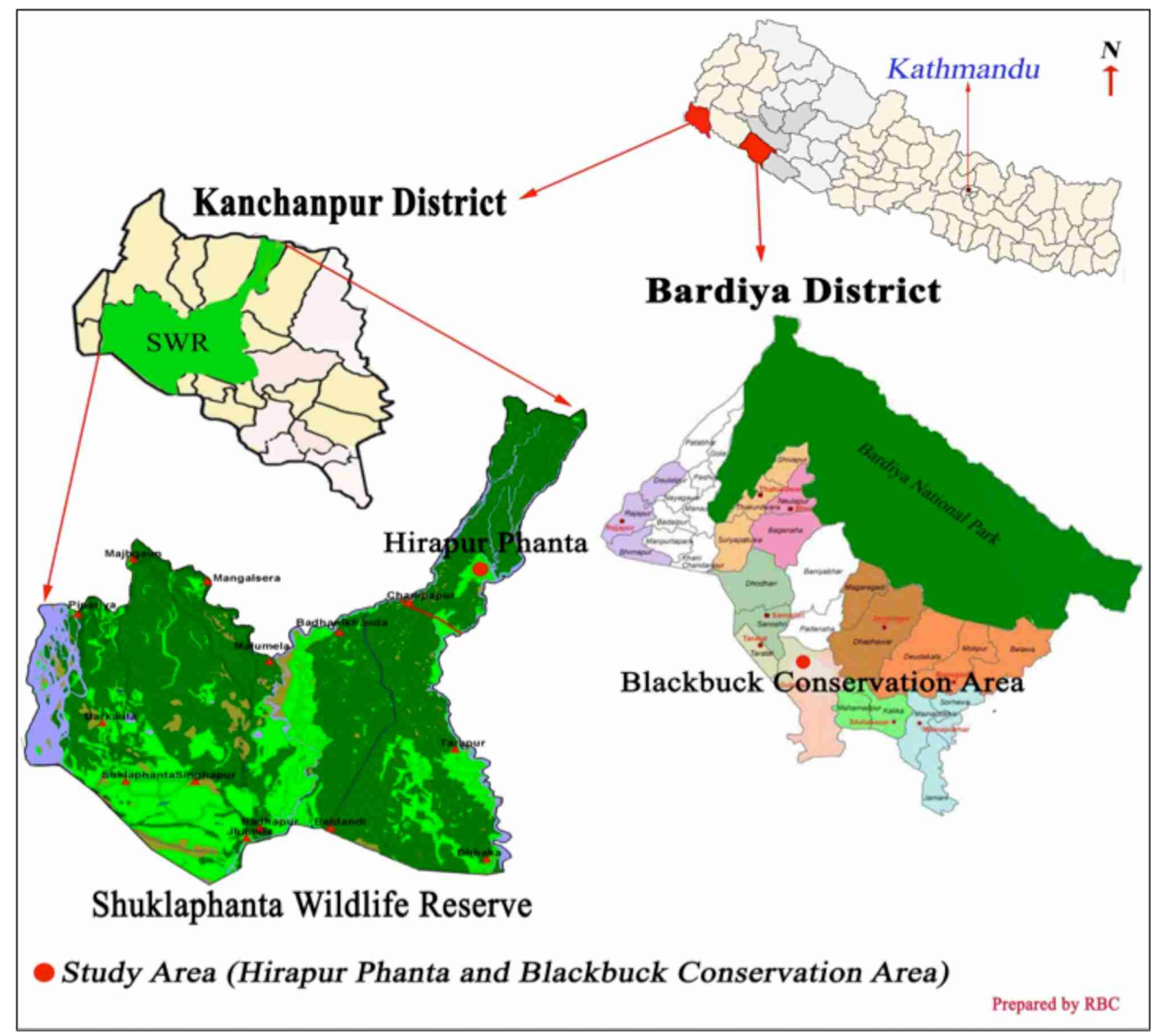

Figure 1 Location of blackbuck conservation area (Map not to scale) 


\section{Sample size}

Out of total 220 fresh faecal samples of blackbuck, 70 samples were collected from Hirapur Phanta of SWR, Kanchanpur and 150 samples from BCA, Khairapur, Bardiya district from June to August 2013.

\section{Sample collection method}

At first, the major habitat of blackbuck was determined and observed the position of defecation and urination according to sex, in order to collect the fresh faecal samples with help of blackbuck's caretaker. In the next day early morning or sunset time, proper care was taken when an animal defecated and sex was identified, then the fresh sample was collected in sterile vial from field immediately to prevent contamination (Plate 1, Photo 1-6).

\section{Preservation of samples}

Collected faecal samples of blackbuck were preserved in 2.5\% potassium dichromate that helps in maintaining the morphology of protozoan parasites and preventing further development of some helminthes eggs and larvae.

\section{Microscopic examination}

All samples were examined at the laboratory of Central Department of Zoology, Tribhuvan University, Kirtipur. The samples were processed for microscopic examination. The ova/cysts/oocysts and larvae of different parasites were identified according to the morphology and quantitative estimation by using Saline and Iodine wet mount and concentration methods (floatation and sedimentation) and Stoll's ova dilution technique to determine eggs per gram (EPG), cyst per gram (CPG), oocyst per gram (OPG) of faeces (Soulsby, 1982).

\section{Data analysis}

The association of parasitic infection between BCA and SWR as well as among the endo-parasites calculating the chi-square values and probability (P-value) at 95\% confidence level at various degree of freedom (d.f) using the software SPSS version 19.

\section{Results and Discussion}

Blackbucks of both the study area (BCA and SWR) were found to be infected with protozoan as well as helminthes parasites. The overall prevalence of parasites was found to be $90.0 \%$ in BCA and SWR. The highest prevalence may be due to favorable climatic conditions, constant exposure of infestation and availability of infective stage larvae on the grazing ground by animals (Lama et al., 2015; Opara et al., 2010). Furthermore, samples were taken during rainy season, i.e. from June to August. This might be the reason for the highest prevalence of parasites. Sufficient rainfall and moisture during wet season favor the survival of infective larvae in pasture and higher probability of uptake of the infective larvae leading to higher prevalence rate (Kuchai et al., 2010). The characteristics of cyst, oocysts and eggs of the identified parasites are shown in Table 1.

\section{Protozoan parasitic infection in blackbucks}

Protozoan parasitic infection in blackbucks was found to be $55.33 \%$ and $55.71 \%$ in BCA and SWR respectively. In both of the study area, fawns were infected more (60\%) compared to both the sexes of blackbucks. Even though, the difference was statistically significant in $\mathrm{BCA}(\mathrm{P}=0.001)$, it was insignificant in SWR $(\mathrm{P}=0.667)$. The blackbucks of both the study area were highly infected with Eimeria sp. parasites than Entamoeba sp. (Fig. 2). The result indicated the maximum fawns were infected by Eimeria sp. with and without micropyle group. The distribution of each species of protozoan parasites are not statistically significantly different in between BCA and SWR ( $\mathrm{P}=0.958)$. Due to coccidiosis, the infected hosts generally exhibit loss of appetite, weakness, diarrhoea, particularly in fawns than the adults, resulting in the compromised immune system (Ghimire et al., 2008) indicating its high impact on the survival of Bblackbuck.

\section{Trematodes}

Prevalence of trematode parasitic infection observed in blackbuck of BCA and SWR were $34.67 \%$ and 50\% respectively. These prevalence rates are almost comparable with the results presented earlier (Ban 2012; Khanal, 2006). Blackbucks of both study area were found highly infected with intestinal fluke, Paramphistomum sp. in compared to liver-fluke, Fasciola sp. However, infection of blood-fluke (Schistosoma sp.) was found only among the blackbucks of SWR (Fig. 3). It indicates that appropriate snail intermediate hosts exist in both study area. Paramphistomum sp. and Fasciola sp. have been reported earlier from Blackbucks (Ban, 2012; Rao \& Acharjyo, 1972; Rimal, 2011). The result revealed high prevalence of trematode parasitic infection in adult blackbucks of both sexes than the fawns.

\section{Cestodes}

The cestode parasites identified in the faecal examination of wild ruminants of various part of the world are Taenia bydatigena, Moniezia expansa and M. benedeni (Bogale et al., 2014; Frooq et al., 2012; Kuzmina et al., 2010; Mohammad et al., 2012) and in Nepal (Ban, 2012; Thapa, 2013). However, the present study hasn't found Taenia sp. in any samples, but genus Moniezia has been isolated in some samples. The prevalence rate of Moniezia sp. was observed to be $14 \%$ in blackbuck of BCA, which is higher than the earlier reports (Ban, 2012).

\section{Nematodes}

Blackbucks were found highly infected by nematode parasites than others. Out of the total samples examined, 89.33\% samples of BCA and $81.43 \%$ samples of SWR were positive for gastrointestinal nematode parasites. Among them, Trichostrongylus sp. (75.55\%) was the highly prevalent in Blackbuck of BCA followed by Ascaris (57.33\%), Haemonchus sp. (18\%), Strongyloides sp. (16\%), Bunostomum sp. (12.67\%), Trichuris sp. (6\%) and Oxyuris sp. (4.67\%) (Fig. 4). The nematode Haemonchus contortus (wire 
Table 1 Characteristics of cyst, oocyst and eggs of blackbuck parasities

\begin{tabular}{|c|c|c|c|c|c|}
\hline Class & Genera & Size $(\mu \mathrm{m})$ & Characteristics & ate No. & Photo No. \\
\hline Sporozoa & Eimeria sp. & $\begin{array}{c}34.5+19.5 \\
\text { (without micropile) }\end{array}$ & $\begin{array}{l}\text { small with morula located centrally or sub-centrally } \\
\text { or completely filled up, Micopile onone side. }\end{array}$ & 2 & $1 \& 2$ \\
\hline Sarcodina & Entamoeba sp. & $30+6$ ( diameter $)$ & small, rounded or spherical having four nucleus & 2 & 3 \\
\hline \multirow[t]{3}{*}{ Trematoda } & Fasciola sp. & $135+15 \times 79.5+4.5$ & $\begin{array}{l}\text { Oval, unsegmented thin shell containing an ovum and } \\
\text { cluster of yolk cells, morula sub-central, operculum } \\
\text { usually indistinct }\end{array}$ & 2 & 4 \\
\hline & Paramphistomum sp. & $165+5 \times 82.5+7.5$ & $\begin{array}{l}\text { operculum in one pole, containing five blastomeres } \\
\text { surrounded by about } 50 \text { yolk cells, morula centrally or } \\
\text { somewhat sub centrally }\end{array}$ & 2 & 5 \\
\hline & Schistosoma sp. & $147+3 \times 75$ & $\begin{array}{l}\text { spindle shaped, flattened at one side, greatly elongated } \\
\text { slender posterior spine at another end }\end{array}$ & 2 & 6 \\
\hline Cestoda & Moniezia sp. & $70.5+4.5$ & $\begin{array}{l}\text { triangular or; somewhat irregular having a circular or } \\
\text { pear shaped (pyriform) apparatus at one end }\end{array}$ & 2 & 7 \\
\hline \multirow[t]{7}{*}{ Nematoda } & Trichostrongylus sp. & $81+6 \times 48+12$ & $\begin{array}{l}\text { oval or bean shaped, central mass usually in } 8-12 \text { cell } \\
\text { stages, }\end{array}$ & 3 & 1 \\
\hline & Ascaris sp. & $31.5+7.5$ & $\begin{array}{l}\text { spherical, granular contents and unsegmented, thick } \\
\text { aleveolated albuminous shell }\end{array}$ & 3 & 2 \\
\hline & Stongyloides sp. & $88.5+7.5 \times 52.5+7.5$ & $\begin{array}{l}\text { Small, oval with round edges or ellipsoidal, thin shelled } \\
\text { containing fully developed larvae }\end{array}$ & 3 & $3 \& 4$ \\
\hline & Trichuris sp. & $75 \times 36$ & $\begin{array}{l}\text { unsegmented embryo, barrel shaped with a transparent } \\
\text { plug at either pole }\end{array}$ & 3 & 5 \\
\hline & Haemonchus sp. & $80+5 \times 48+12$ & $\begin{array}{l}\text { oval, thin shelled, hyaline, elongated, large and round, } \\
\text { segmented (embryonated) when deposited }\end{array}$ & 3 & 6 \\
\hline & Bunostomum sp. & $95+5 \times 46.5+1.5$ & 4-8 blastomeres, thick and rectangular walls. & 3 & 7 \\
\hline & Oxyuris sp. & \multicolumn{2}{|c|}{$112.5+7.5 \times 55.5+19.5$ bean shaped, embryonic mass surrounded by sticky fluid } & iid 3 & 8 \\
\hline
\end{tabular}

BCA SWR

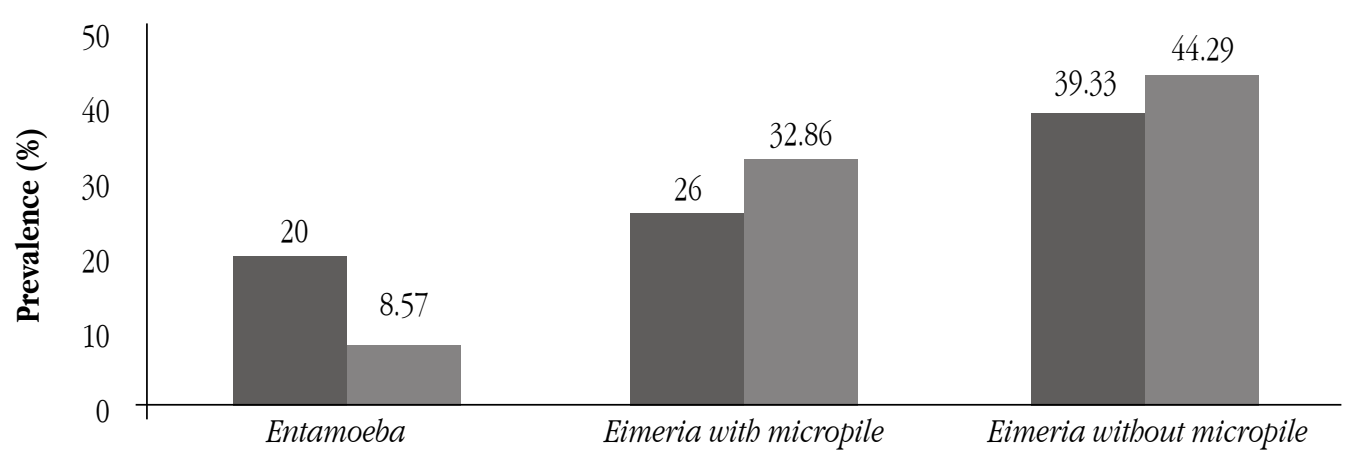

Figure 2 Protozoan parasitic infections in blackbucks of BCA and SWR

worm) is one of the most important pathogens for blackbuck (Thorton et al., 1973), producing a disease known as haemonchiasis which can cause anemia, growth loss, edema, emaciation, and even death (Roberts \& Janovy, 2005). Three species of
Trichostrongylus encountered in blackbuck include Trichostrongylus axei, T. colubriformis and T. probolurus (Thornton et al., 1973) and T. retortaeformis, T. vitrinus and $T$. capricola in other wild ruminants (Kuzmina et al., 2010; Mayo et

\section{棈: TU-CDES}


al., 2013; Mohammd et al., 2012). Three species of Trichuris sp. that have been described in previous reports include T. globulosa, T. cervicaprae and T. ovis (Goossens et al., 2005; Thornton et al., 1973,). In the present study, Trichuris sp. (6\%) was isolated from blackbuck of BCA only. This shows that blackbuck of BCA are more infected with Trichuris sp. as compared to 4.19\% and 3.26\% recorded by Bogale et al. (2014) and Ban (2012), respectively.

This result shows that the blackbuck Conservation Areas are highly infected with Ascaris sp. eggs. A characteristic Ascaris sp. egg was also found to be distributed in many faecal samples of the present study. Likewise, the prevalence of Bunostomum sp. in the present study was found to be $12.67 \%$ and $2.86 \%$ in blackbuck of BCA and SWR respectively. The prevalence (4.67\%) of Oxyuris sp. was observed in faecal samples of blackbuck of BCA only. This is much lower than result of Thapa (2013) who revealed $88.24 \%$ prevalence in Himalayan Thar and $70.59 \%$ prevalence in barking deer.

\section{Mixed infection}

Maximum blackbucks of the BCA were found to be infected with multiple parasitic infections in which combination of species like Paramphiostomum sp., Ascaris sp. and Trichostrongylus sp. were common (Fig. 5). While in SWR, double parasitic infection was most common as compared to triple and multiple infections. Among them, combination of coccidian parasites and nematode parasite are the most common. The mixed parasitic infections were found to be more common in blackbuck due to high contamination of pasture by grazing of domestic animals and human. The present result was similar to the findings of Thapa (2013) who described the mixed infection as the most common in Himalayan Thar and barking deer.

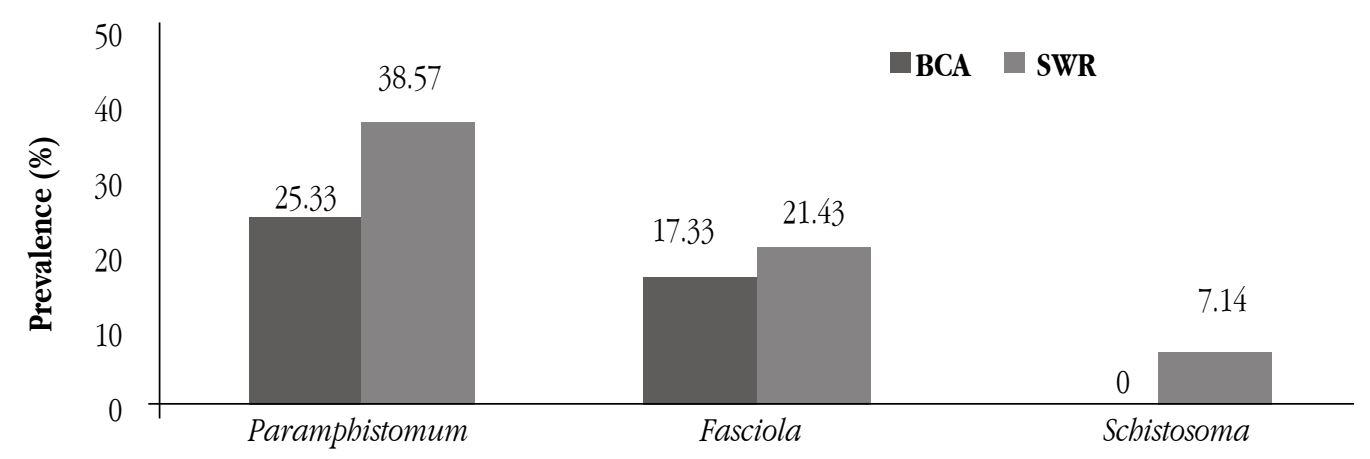

Figure 3 Trematode parasitic infection in blackbucks of BCA and SWR

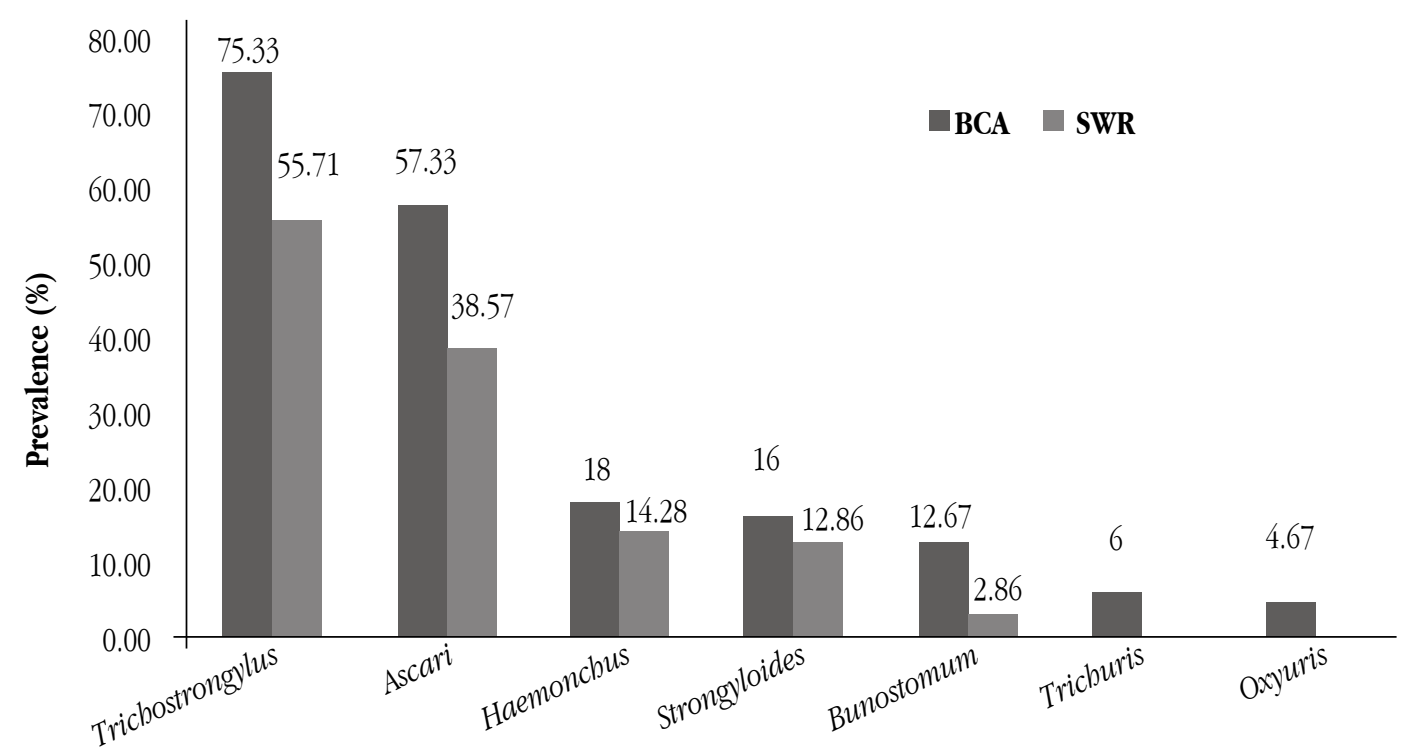

Figure 4 Nematode parasitic infections in blackbucks of BCA and SWR 


\section{$\square \mathrm{BCA} \quad$ SWR}

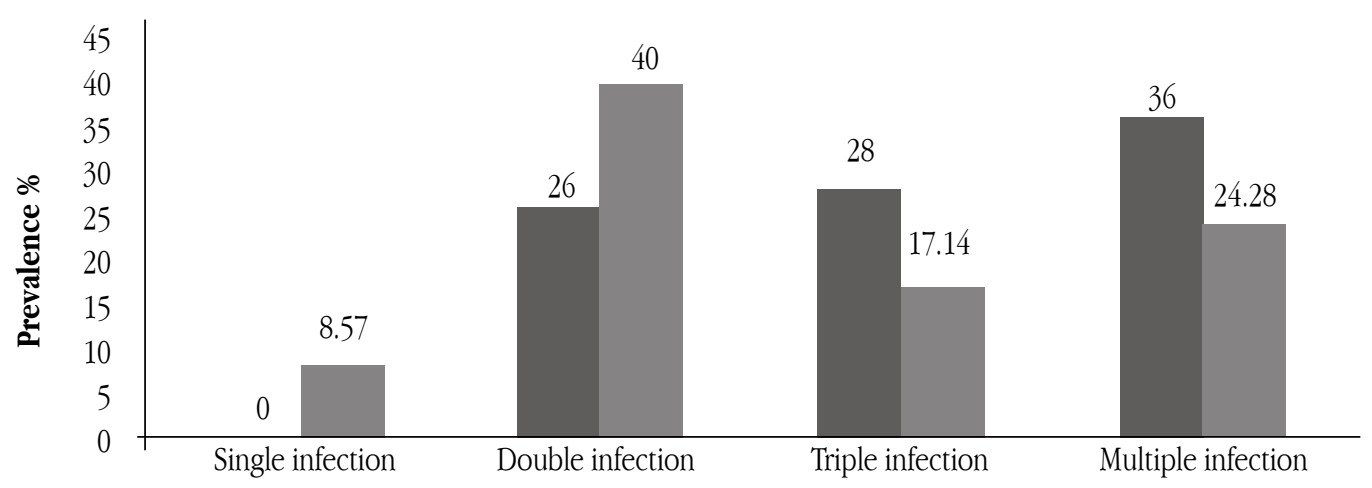

Figure 5 Mixed parasitic infection in BCA and SWR

\section{Parasitic load in blackbuck of BCA and SWR}

The parasitic load in blackbuck was assessed based on the number of eggs/oocysts. The mean of EPG/OPG/CPG was calculated in all of the positive samples (Table 2). Among protozoans, the highest CPG (300) was found in Blackbuck due to Eimeria sp. than Entamoeba sp. Among trematodes, the highest parasitic load of Paramphistomum sp. was found to be 450 followed by Fasciola sp. and Schistosoma sp.; while among nematodes, the highest EPG of Trichostrongylus sp. was 700, followed by Ascaris sp (400), Strongyloides sp, Haemonchus sp, Bunostomum sp, Trichuris sp and Oxyuris sp.

Table 2 Parasitic load in blackbuck of BCA and SWR

\begin{tabular}{llcc}
\hline Class & Name of genera & \multicolumn{2}{c}{ Parasitic load (EPG/OPG/CPG) } \\
\hline \multirow{3}{*}{ Sarcodina } & Entamoeba sp. & Range & Average \\
Sporozoa & Eimeria sp. & $200-300$ & $250 \pm$ \\
Trematoda & Paramphistomum sp. & $200-700$ & 300 \\
& Fasciola sp. & $100-600$ & 450 \\
& Schistosoma sp. & $100-300$ & 350 \\
Cestoda & Moniezia sp. & $100-600$ & 350 \\
Nematoda & Trichostrongylus sp. & $100-1300$ & 700 \\
& Ascaris sp. & $300-500$ & 400 \\
& Haemonchus sp. & $100-400$ & 250 \\
& Stongyloides sp. & $200-400$ & 300 \\
& Bunostomum sp. & $100-200$ & 150 \\
& Trichuris sp. & 100 & 100 \\
& Oxyuris sp. & $100-300$ & 200 \\
\hline
\end{tabular}

\section{Conclusion}

Blackbucks of both BCA and SWR were found to be highly infected with protozoan, trematode, cestode and nematode parasites. Parasitic genera identified infecting blackbucks includes Eimeria sp. and Entamoeba sp. among protozoans, while Paramphistomum sp., Fasciola sp. and Schistosoma sp. among trematodes; Trichostrongylus sp. Ascaris sp., Haemonchus sp., Strongyloides sp., Trichuris sp., Oxyuris sp. and Bunostomum sp. among nematodes and Moniezia sp. among cestode parasites. Mixed parasitic infection was found common in blackbucks of both the study area due to high contamination of pasture lands. The highest parasitic load was found to be 700 revealed by Trichostrongylus sp. among all GI parasites. The result indicated that blackbucks are highly susceptible to endo-parasites. Therefore, proper pasture management programme and control strategy should be conducted in BCA and SWR in order to upgrade the health status and conservation of blackbuck in Nepal.

\section{Acknowledgements}

The authors would like to sincerely acknowledge the Office of the DNPWC for granting permission to conduct the study in the BCA and SWR. The cooperation of wardens, Ranger and wildlife technicians of BCA and SWR are gratefully acknowledged.

\section{References}

Akter, R., \& Arshad, M. (2006). Arid rangelands in the Cholistan desert (Pakistan). Secheresse, 17(1-2), 210-217.

Ban, S. (2012). Conservation status of Blackbuck (Antilope cervicapra Linneaus, 1758) at Khairapur, Bardia, Nepal. Master's Thesis. Central Department of Zoology, TU, Kirtipur, Nepal. Bogale, B., Melaku, A., Chanie, M., Fentahun, T., \& Berhanu, A. (2014). First report of helminth parasites of Walia ibex (Capra walie) at Simen Mountains National Park, Natural World Heritage Site, Northern Ethiopia. International Journal of Animal and Veterinary Advances, 6(1), 1-4.

Burton, J. A., \& Burton, V.G. (1987). Collins Guiide to Rare Mammals of the World. London: Collins

Corbett, G.B., \& Hill, J.E. (1977). The Mammals of Indo-Malayan Region; A systemic review; Natural History Museum Publication. Oxford University Press, New York, USA.

DNPWC (2009). Annual Report of Blackbuck Conservation Area, Kathmandu, Nepal. Department of National Park and Wild life Conservation, Nepal.

DNPWC (2012). Wildlife Nepal. Newsletter. No. 2. Department of National Park and Wildlife Conservation, Kathmandu.

\section{㓱TU-CDES}


Farooq, Z., Mushtaq, S., Iqbal, Z., \& Alchtar, A. (201)2. Parasitic helminthes of domesticated and wild ruminants in Cholistan desert of Pakistan. International Journal of Agriculture and Biology, 14, 63-68.

Flach, E.J., \& Sewell, M.M.H. (1987). Gastrointestinal Nematodiasis in Blackbuck (Antilope cervicapra) at Edinburgh Zoo. Journal of Zoo Animal Medicine, 18 (2/3), 56-61.

Goossens, E., Domy, P., Boomker, J., Vercammen, F., \& Vercruysse, J. (2005). A 12-month survey of the gastrointestinal helminthes of Antelopes, Gazelles and Giraffids kept at two zoos in Belgium. Veterinary Parasitology, 127, 303-312.

Hossain, N. Md. (2012). Investigation on gastrointestinal parasites in captive wild animals and birds in Bangladesh Sheikh Mujib Safari Park, Dulahazara, Cox's Bazar. Master's Thesis. Department of Parasitology, Bangladesh Agricultural University, Mymensingh.

IUCN (2008). "Antilope cervicapra" IUCN Red List of Threatened Species. accessed on 16 October, 2014.

Khanal, L. (2006). Population status, general behaviour and conservation practices of Blackbuck (Antilope cervicapra, Linneaus, 1758) at Khairapur, Bardiya, Nepal. Master's Thesis. Central Department of Zoology, Tribhuvan University, Kathmandu, Nepal.

Kuchai J.A., Chishti M.Z., Ahmad, F., \& Rasool, M. (2010). Prevalence of Trematode Parasitic Infestation in Yak of Ladakh (Bos grunniens). Pakistan Journal of Wildlife, 1(2), 64-66.

Kuzmina, T., Kharchenko, V., \& Malega, A. (2010). Helminth fauna of Roe deer (Capreolus capreolus) in Ukraine: Biodiversity and Parasite Community. Vestinik Zoologii, 44(1), 12-19.

Lama, S.T., Lama, R.P., Regmi, G.R., \& Ghimire, T.R. (2015). Prevalence of intestinal parasitic infections in free-ranging red panda (Ailurus fulgens Cuvier, 1825 (Mammalia: Carnivora: Ailuridae) in Nepal. Journal of Threatened Taxa, 7(8), 74607464.

Lydekker, R. (1924). The game animals of India, Burma, Malaya and Tibet (1907), revised by J.G Dollman, London: Rowland Ward.

Mallon, D.P., \& Kingswood, S.C. (2001) (Compilers). Antelopes: Global survey and Regional Action Plan. Vol. 4. IUCN. p.184.

Mayo, E., Ortiz, J., Martinez-Carrasco, C., Garijo, M.M., Espeso, G., Hervias, S., et al. (2013). First description of gastrointestinal nematodes of Barbary sheep (Ammotragus lervia).Veterinary Research Communication, 37(3), 209-215.
Mohammed, O.B., Alagaili, A.N., Omer, S.A., \& Hussein, M.F. (02012. Parasites of the Arabian Oryx (Oryx leucoryx, Pallas, 1777) and their prevalence in the Kingdom of Saudi Arabia. Comparative Parasitolgy, 79(2), 288-292.

Muoria, P.K., Muruthi, P., Rubenstein, D., Oguge, N.O., \& Munene, E. (2005). Cross-sectional survey of gastrointestinal parasites of Grevy's zebras in southern Samburu, Kenya. African Journal of Ecology, 43, 392-395.

Opara, M.N., Osuji, C.T., \& Opara, J.A. (2010). Gastrointestinal parasitism in captive animals at the zoological garden, Nekede Owerri, Southeast Nigeria. Report and Opinion, 2(5), 21-28.

Pradhan, N.M., Bhatta, S.R., Jnawali, S.R., \& Pathak, S.R. (1999). Blackbuck Conservation Study Report. Royal Bardiya National Park, Bardiya, Nepal (Script in Nepali).

Ranjitsinh, M.K. (1989).The Indian Blackbuck. Nataraj Publisher, Deharadun.

Rao, A.T., \& Acharjyo, L.N. (1972). Further observations on fasciolosis among wild ungulates at Nandan Kanan Zoo. Indian Veterinary Journal, 49, 133-135.

Rimal, S. (2011). Prevalence of helminth parasites in deer of Mrigasthali forest, Pashupati, Kathmandu. Proceeding of 10th National Vet. Conference on 28-30 March 2012. Nepal Academy Hall, Kamaladi, Kathamandu, 29-30.

Roberts, L.S., \& Janovy, J. (2005). Gerald Schmidt and Larry Robert's Foundation of Parasitology. 7th Ed. New Work, NY: McGrawHill.

Shah, M. (2012). Annual Report 2011/12. Blackbuck Conservation Area Office, Khairapur, Bardiya.

Soulsby, E.J.L. (1982). Textbook of Veterinary Clinical Parasitology. Vol. I, Helminths Oxford Blackwell Scientific, London.

Thornton, J.E., Galvin, T.J., Bell, R.R., \& Ramsey, C.W. (1973). Parasites of the Blackbuck (Antilope cervicapra) in Texas, US. Journal of Wildlife Diseases, 9(2), 160-162.

Thapa, C. (2013). Prevalence of gastrointestinal parasites of Himalayan Thar (Hemitragus jemlabicus) and Barking deer (Muntiacus vaginalis) of Rara National Park, Nepal. Master's Thesis. Central Department of Zoology, Tribhuvan University, Kirtipur, Kathmandu, Nepal. 


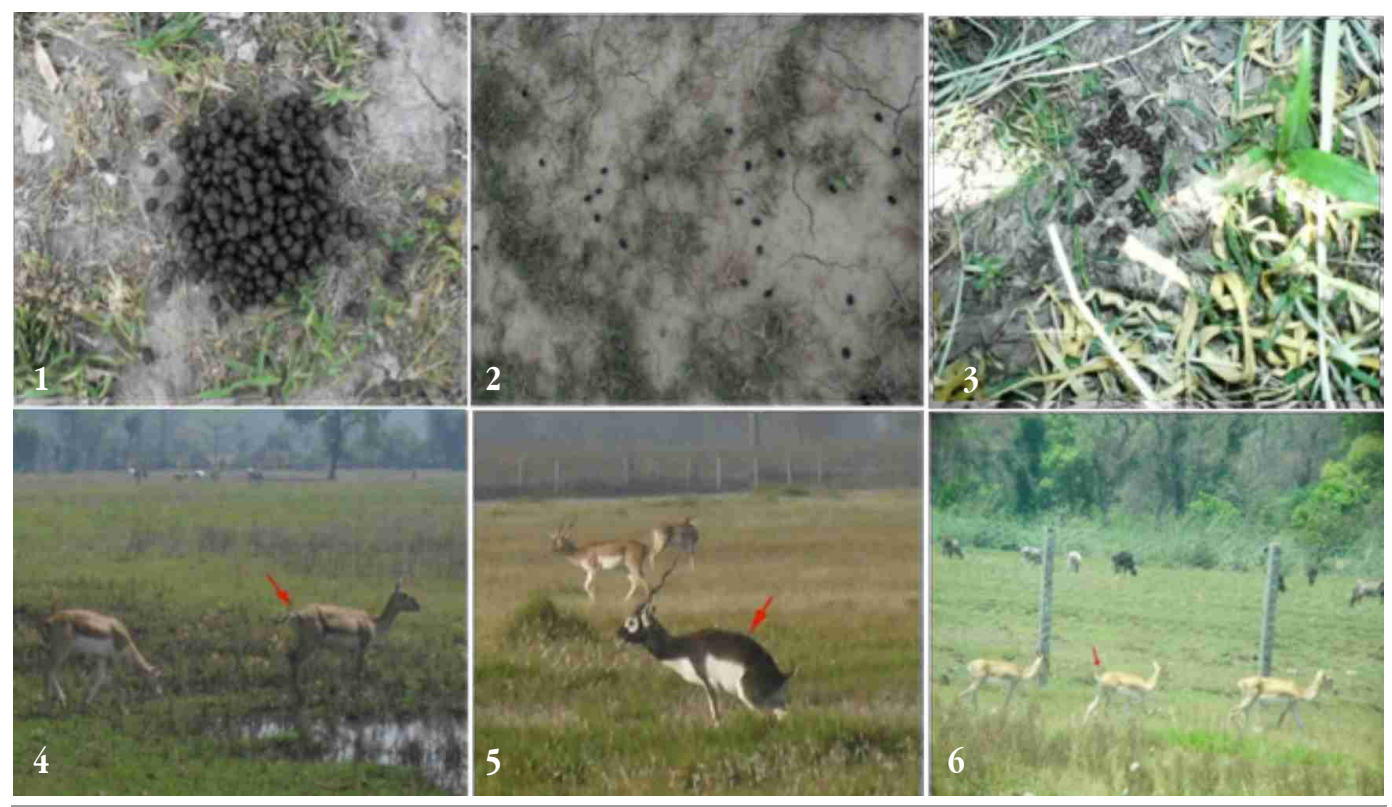

Plate 1: Photoes 1. Facal pellet of male, 2. Faecal pellet of female, 3. Faecal pellet of fawn, 4. defecating position of female, 5 . Defecating position of male, 6 . Defecating position of fawn
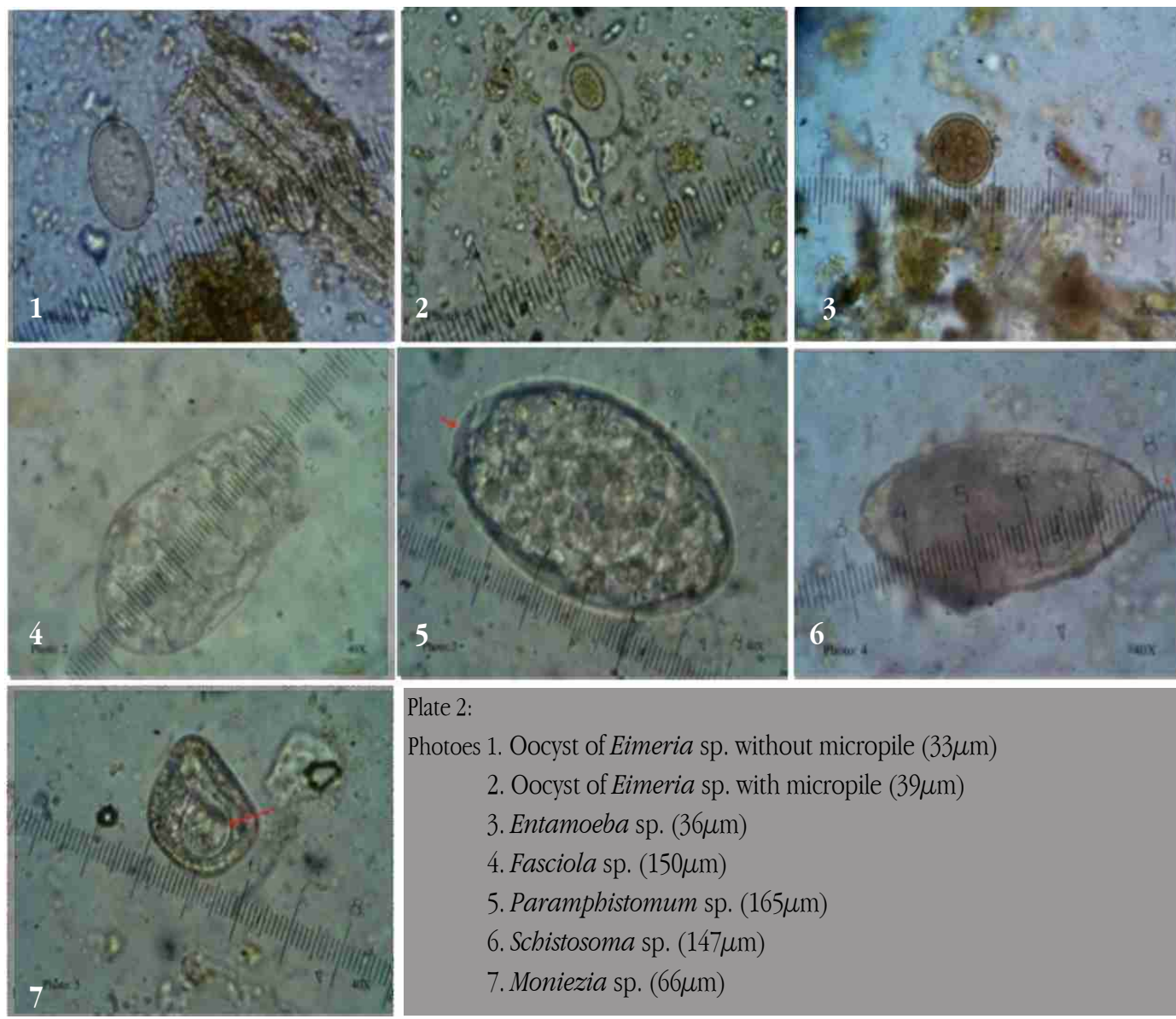

Plate 2:

Photoes 1. Oocyst of Eimeria sp. without micropile $(33 \mu \mathrm{m})$

2. Oocyst of Eimeria sp. with micropile $(39 \mu \mathrm{m})$

3. Entamoeba sp. $(36 \mu \mathrm{m})$

4. Fasciola sp. $(150 \mu \mathrm{m})$

5. Paramphistomum sp. $(165 \mu \mathrm{m})$

6. Schistosoma sp. $(147 \mu \mathrm{m})$

7. Moniezia sp. $(66 \mu \mathrm{m})$ 


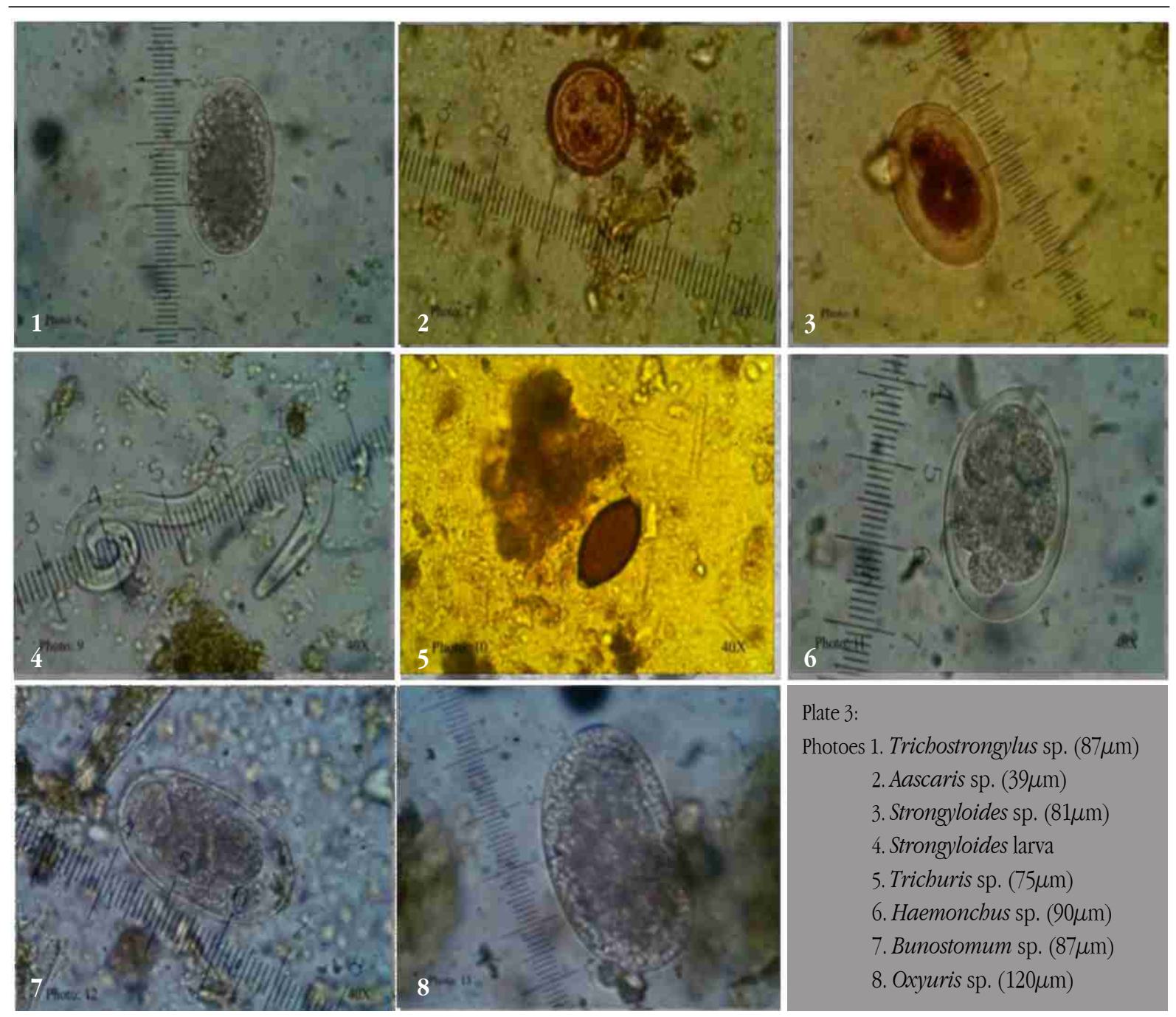

